\title{
Audífonos inalámbricos para un espectáculo teatral en Costa Rica: diseño de sistema para 96 espectadores
}

\author{
Wireless Headphones for \\ a Theatrical Performance in Costa Rica: \\ Sound System Design for 96 Attendees
}

José Manuel Conejo

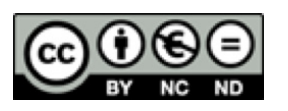

Esta obra está bajo una licencia Creative Commons Reconocimiento-No comercial-Sin Obra Derivada 


\title{
Audífonos inalámbricos para un espectáculo teatral en Costa Rica: diseño de sistema para 96 espectadores
}

\author{
Wireless Headphones for \\ a Theatrical Performance in Costa Rica: \\ Sound System Design for 96 Attendees
}

\author{
José Manuel Conejo ${ }^{1}$ \\ Universidad de Costa Rica \\ Costa Rica
}

Recibido: 13 de setiembre de 2018 Aceptado: 23 de noviembre de 2018

\begin{abstract}
Resumen
Los audífonos permiten escuchar detalladamente los sonidos captados o grabados gracias a su capacidad de aislar el oído de ruidos externos. Esto crea un entorno íntimo que facilita la inmersión de la escucha en la experiencia aural. Brindar audífonos inalámbricos a la audiencia de los espectáculos teatrales en Costa Rica podría aumentar la inteligibilidad de los diálogos actorales con el uso de micrófonos, reducir la intrusión de ruidos ajenos a la historia representada en la escena y resaltar, con detalle, los estímulos sonoros del espectáculo. En Costa Rica, no existen registros de espectáculos que hayan utilizado audífonos para entregar su sonido a la audiencia, por lo que resulta difícil valorar su impacto estético. Ante la falta de un referente técnico para lograr un sistema de sonido basado en audífonos, este documento propone un diseño técnico de un sistema que realiza la transmisión de la señal de forma inalámbrica.
\end{abstract}

Palabras clave: audífonos; inalámbrico; teatro; diseño; sonido

1 Profesor de la Escuela de Artes Dramáticas de la Universidad de Costa Rica. Máster en especialidades visuales, teatrales y escénicas con énfasis en Diseño de Sonido. Correo electrónico: josemanuel.conejo@ucr.ac.cr 


\begin{abstract}
Headphones allow to critical listen captured and recorded sound thanks to their ability to isolate the listener from the environment. This fact creates an intimate space that helps to immerse the listener into the aural experience. Providing headphones to Costa Rican theatrical shows attendees might help to increase acting dialog's intelligibility by using dedicated microphones, reduce outside undesirable noises that distract audience from on stage representation and to enhance the show' sound stimuli. There are no records of theatre headphone shows in Costa Rica, then is difficult to evaluate its artistic impact. Given the fact there is no technical documentation that helps to replicate such a system, this paper addresses this issue by proposing a wireless headphone system design.
\end{abstract}

Keywords: headphones; wireless; theater; design; sound. 
Audífonos inalámbricos para un espectáculo teatral en Costa Rica:

Artículos diseño de sistema para 96 espectadores

\section{Problema por resolver}

Como diseñador de sonido para espectáculos teatrales, mi tarea es brindar a la audiencia una experiencia sonora que le permita conectarse emotivamente con los sucesos de los personajes que accionan la escena. Esta experiencia se logra al diseñar y crear los estímulos sonoros a reproducir en el espectáculo, a través de un sistema de audio también diseñado, calibrado y operado bajo los criterios estéticos acordados entre el director del montaje y mi persona. Este tipo de experiencias auditivas se logran por medio de los altavoces, dispuestos en la mayoría de los sistemas de audio instalados en los teatros de nuestro país. Sin embargo, estos sistemas de audio no satisfacen todo el tiempo las necesidades creativas de los y las directoras teatrales de Costa Rica. En este sentido, fui consultado por la colega Natalia Mariño, directora de teatro, sobre la necesidad de tener un sistema de sonido basado en audífonos inalámbricos para un espectáculo en 2018 que, lamentablemente, no fue posible realizar. No obstante, la inquietud de saber si era posible crear tal sistema quedó latente. Me di a la tarea de investigar nuestros referentes históricos costarricenses para saber si en el pasado se había hecho algún espectáculo teatral con características iguales o semejantes. Lamentablemente, no fue posible encontrar un registro sobre este tema, por lo que el presente documento plantea como problema diseñar un sistema sonoro que permita la transmisión de sus elementos de forma inalámbrica, a cada uno de los audífonos de los espectadores presentes en un espectáculo, usando dispositivos profesionales de transmisión de audio, de venta en nuestro país. El problema en cuestión evalúa la viabilidad de los componentes, la interacción de estos con otros dispositivos del sistema, el costo de adquirirlo o implementarlo, lo cual prevé las condiciones de muchos teatros independientes de nuestro país, que buscan expandir la experiencia sensorial de sus públicos. El problema presentado en este documento trata de resolver y anticipar situaciones de nivel técnico, mas no analiza ni evalúa su impacto estético, puesto que no existe un espectáculo en el cual este sistema haya sido probado. Sin embargo, se espera que el diseño del sistema sonoro y sus posibilidades técnicas inspiren a otros diseñadores de sonido y directores teatrales a abordar, implementar y explorar esta alternativa en sus espectáculos.

\section{Abordaje del diseño: cómo fluirá la señal en nuestro sistema de audífonos inalámbricos}

Aunque los audífonos inalámbricos son el fin de nuestra propuesta, he de señalar que, para que estos tengan sentido o valor como elemento activo de un espectáculo teatral, han de ponerse en un contexto y han de evaluarse como parte de un sistema. Es decir, no hablaré de los audífonos de forma aislada: ingeniería y ciencia que explica cómo los audífonos emiten sonido, sino de cómo estos son tratados de forma hipotética en función de un espectáculo teatral. Al entender que los audífonos son conectados a otros dispositivos, 
es necesario hacer hincapié en los componentes que conforman la cadena. La señal (por consiguiente, la narrativa de este documento) viajará del siguiente modo: sala teatral $\rightarrow$ actores/micrófonos $\rightarrow$ reproducción de fuentes sonoras en computadora $\rightarrow$ mesa de mezcla $\rightarrow$ transmisores inalámbricos $\rightarrow$ receptores inalámbricos $\rightarrow$ audífonos. Al hacer esta breve aclaración, pasemos, pues, a revisar rápidamente algunas experiencias de este tipo en espectáculos teatrales en otros países.

\section{Algunos antecedentes de sistemas de audio basados en audífonos para audiencias teatrales}

La transmisión del sonido de un espectáculo a través del uso de audífonos se está convirtiendo en una tendencia común, en algunos teatros británicos, alemanes y estadounidenses. Esto debido a las bondades de los audífonos para crear un entorno sonoro más íntimo y próximo que los altavoces. En ese sentido, Matt Trueman comenta en el diario británico The Guardian:

In these theatre pieces, listening is a part of the overall experience, rather than the whole ... Where sound is transmitted live, as in David Rosenberg's Contains Violence (where the audience watches the action through binoculars from a roof top across the street, hearing the dialogue through headphones), this sound-vision relationship makes sense. The audio device becomes a way of amplifying the dialogue, like a one-way walkie-talkie [En estas piezas teatrales, la escucha es parte de la experiencia y no el todo ... Cuando el sonido se transmite en vivo, como es el caso de Contains Violence de David Rosenberg (donde la audiencia mira la acción a través de binoculares desde una azotea a una calle y el diálogo se escucha por audífonos), esta relación sonido-visión tiene sentido. El audio se vuelve una forma de amplificar el sonido, como un walkie-talkie] (Trueman, 2018, párr. 5).

Martin Gimenez reconoce en su blog No Proscenium que "sound is the one design element that easily projects beyond the fourth wall - be that a stage or screen-and immerses the audience [el sonido es el elemento de diseño que fácilmente se proyecta más allá de la "cuarta pared" - sea esta el escenario o la pantalla - y sumerge a la audiencia]" (Gimenez, 2018, párr. 1). Así, el sonido en los espectáculos teatrales puede crear una sensación envolvente a través de sistemas 5.1, como en el cine (experiencia que ya es posible en nuestro Teatro Universitario de la Universidad de Costa Rica) o a través del sonido binaural. Giménez destaca, además, el uso combinado de audífonos-micrófono binaural en el espectáculo The Encounter de Simon McBurney, estrenado en 2016 en Broadway, para intensificar la espacialidad y el efecto realista de la audición del ser humano. Sobre el mismo espectáculo, Gareth Fry y Pete Malkin, diseñadores de sonido del espectáculo, declaran que: "this is the 
Audífonos inalámbricos para un espectáculo teatral en Costa Rica:

Artículos diseño de sistema para 96 espectadores

first show on Broadway to use binaural sound, as far as we're aware ... And also probably the first where the audience wears headphones [es el primer espectáculo en Broadway en usar sonido binaural ... y quizá el primero en el que la audiencia lleva audífonos]" (Reesman, 2018, párr. 2). The Encounter recrea la historia del fotógrafo de National Geographic, Loren McIntyre, quién se extravió en lo profundo de los bosques de la Amazona en 1969. El espectáculo utiliza el sonido como único recurso dramático. Aunque el único actor en escena, el mismo Simon McBurney, actúa frente al micrófono binaural Neumann KU-100, los diseñadores de sonido agotan hasta el último recurso sonoro disponible (efectos sonoros, música, locuciones en vivo) para, literalmente, crear el Amazonas y las peripecias de Loren en las mentes de las personas.

Como explicaba al principio de este documento, yo nunca he experimentado un espectáculo en el cual los diálogos actorales, la música, los ambientes y efectos sonoros hayan llegado a mis oídos a través de un par de audífonos, sean estos conectados a algún dispositivo o de forma inalámbrica. Sin embargo, mi colega, la directora Natalia Mariño, quien estuvo recientemente en Alemania, tuvo la oportunidad de experimentar el espectáculo Beute Frauen Krieg, dirigida por Karin Henkel (Schauspielhaus Zürich, 2018). El espectáculo, que cuenta los acontecimientos de la Guerra de Troya, desde la perspectiva de una mujer, utiliza audífonos inalámbricos "a la medida" para permitir el desplazamiento de la audiencia (unos trescientos espectadores), por todo el espacio en donde el hecho teatral se lleva a cabo. Esto resulta lógico por los inconvenientes que representan los cables para el desplazamiento en un espacio y, sobre todo, cuando hay trescientas personas transitando en el recinto. De acuerdo con Mariño, todo el diseño sonoro (incluido el diálogo entre los actores) era emitido a través de estos audífonos inalámbricos a la totalidad de la audiencia, que seguía la acción dramática desplazándose a las estaciones situadas en distintos puntos de la sala.

Como directora teatral, Mariño ve un gran beneficio en el uso de audífonos para los espectadores porque permite que la técnica vocal de los actores sea más íntima, cinematográfica si se quiere y que estos parlamentos sean escuchados con facilidad por los espectadores. Desde luego, que los audífonos sean inalámbricos potencia la idea de diseñar una obra en la que los espectadores puedan desplazarse y que el sonido los "siga" a todos lados, sin perder detalle sonoro alguno. Es decir, desplazamiento del público con el sonido de forma inalámbrica. Pero, sin limitarnos a estos particulares, la tecnología que hace posible la transmisión inalámbrica de sonido, al menos desde la mesa de sonido a unos audífonos en el escenario, no es cosa ajena ni novedosa: basta con tener un trasmisor fijo y un receptor inalámbrico que permita conectar audífonos directamente. Los sistemas de monitoreo personal o IEM (in ear monitor, por sus siglas en inglés) permiten a los músicos y actores recibir mensajes y sonidos de forma discreta e inalámbrica. Esto sin necesidad de tener monitores de piso en el escenario, que a muchos directores y músicos molesta por estar en la línea 
visual del público. Cuando se trata de cuatro o cinco músicos en escena, el sistema no es nada complicado y se proyecta igual de simple para cien o doscientos espectadores. Exploraremos, entonces, las posibilidades que estos sistemas ofrecen para diseñar un sistema de audífonos inalámbricos aplicados a un montaje ficticio de Hamlet, en donde, además, valoraremos micrófonos inalámbricos y binaurales, como parte del sistema. Partiendo del supuesto arriba, quizá pueda inspirar a otro u otra colega en diseño sonoro en Costa Rica, que necesite un punto de partida para crear un sistema de transmisión similar.

\section{¿Por qué sistemas IEM y no otros?}

Para diseñar un sistema de sonido para un espectáculo teatral, en Costa Rica, basado en audífonos, podemos anticipar dos categorías: por cable o inalámbrico. En este artículo exploraremos la opción inalámbrica. En corto, el sistema cableado puede ofrecer una buena relación costo-beneficio, puesto que requiere una menor inversión y adquisición de equipo. Sin embargo, el sistema por cable puede resultar inconveniente, debido a todas las líneas que habría que distribuir, por toda el área de audiencia, incluido el cable mismo del audífono. El sistema inalámbrico, mucho más atractivo en estos días debido a que, ya estamos acostumbrados y acostumbradas a nuestros teléfonos celulares y dispositivos móviles, demanda una fuerte inversión de equipo y accesorios para lograr el sistema que, en este caso, eliminaría toda clase de cables, excepto el que se conecta del receptor al audífono. Dentro de los sistemas inalámbricos existe variedad de protocolos de transmisión, pero no todos son convenientes. Por ejemplo, los sistemas basados en luz infrarroja o IR (no visible al ojo humano) son más baratos, pero tienen una baja calidad sonora y al tener longitudes de onda más cortas, en comparación con las ondas de radio, necesitan tener la vía de transmisión libre de obstáculos entre transmisor y receptor. De lo contrario, la transmisión se verá interrumpida con solo el hecho de pasar la mano frente al receptor. El otro gran contendiente es el Bluetooth que, para empezar, tiene una latencia difícil de ignorar, es de fácil acceso para cualquiera que tenga un teléfono celular y solo es posible parear con un receptor a la vez. Además, su protocolo no permite la transmisión de audio en formato Wave ${ }^{2}$ en frecuencias de muestreo de $44.1 \mathrm{kHz}^{3}$ en versiones anteriores a la 4.0.

2 Wave, es junto AIFF, los formatos definidos como estándar profesional por la AES (Audio Engineering Society [Sociedad de Ingeniería en Audio] por sus siglas en inglés) para audio digital. Sus especificaciones están definidas en el "Libro Rojo" de la AES y, de modo simple, define la calidad mínima del Wave del siguiente modo: $44.1 \mathrm{kHz}$ como frecuencia de muestreo y 16 bits de resolución. Estos parámetros aplican para la transmisión de audio en la internet o en su duplicación para discos compactos.

$344.1 \mathrm{kHz}$ fue definida como la frecuencia de muestreo estándar mínima para los archivos de audio

ESCENA. Revista de las artes, 2019, Vol. 79, Núm. 1 (julio-diciembre), pp. 145-176 
Audífonos inalámbricos para un espectáculo teatral en Costa Rica:

Artículos diseño de sistema para 96 espectadores

Finalmente, no es un protocolo recomendado para aplicaciones profesionales, pues según Huntington: "bluetooth is a network primarily designed for short-range connection of peripheral devices, such as wireless headset to a cell phone. It's not well suited for the rigors of the show use, but you might find it useful to connect simple components to a show computer [el bluetooth es una red diseñada primordialmente para funcionar con dispositivos periféricos de rango cercano, como unos audífonos a un teléfono celular. No se ajusta bien a los rigores de un espectáculo, pero podría ser útil para conectar aparatos sencillos a una computadora de espectáculos]" (Huntington, 2012, párr. 2). Cabe resaltar que muchos dispositivos bluetooth se apagan de forma automática, cuando dejan de recibir señal o actividad. En el caso de algunos altavoces bluetooth, estos entran en "modo de reposo" aun cuando reciben señal de audio, pero es enviada a un volumen bajo (por ejemplo: si se conecta un celular a un altavoz bluetooth desde la salida de audio de $3.5 \mathrm{~mm}$ o audífonos por medio de un cable). Lo anterior, supone una desventaja para un espectáculo, pues no se puede garantizar su funcionamiento continuo sin apagarse en ausencia de señal.

Por tanto, llegamos a los sistemas de radiofrecuencia, en donde encontramos los dispositivos IEM, los cuales han resultado ser más confiables a nivel de audio profesional por décadas. Además, permiten un mayor control y configuración de los aparatos. Es por eso que se analizará la opción de estos sistemas, en este documento, como alternativa para un sistema de audio por audífonos inalámbricos en un espectáculo teatral. La diferencia fundamental entre el sistema IEM y el bluetooth radica, mayormente, en que el audio no necesita conversión digital, puesto que trabaja con radiofrecuencias. Otra ventaja es que un solo transmisor puede enviar señal a muchos transmisores a la vez y lo único que necesitan para lograrlo es sintonizarse al mismo canal. Funciona del mismo modo en que una radio convencional sintoniza una radio emisora para escuchar su programa favorito. Otra ventaja es que, de ser necesaria la amplificación de señal, se pueden agregar antenas dentro del teatro, para evitar pérdidas o interrupciones de señal en el recinto. Estas y otras características agregan valor al uso de esta opción inalámbrica. Para desarrollar mi argumento, voy a crearnos una situación ficticia para un teatro real: un espectáculo a la italiana en el que asisten noventa y seis espectadores, que es la cantidad usual de público que el inmueble puede alojar a "teatro lleno". El recinto que usaremos como modelo será el Teatro Universitario (T.U.) de la Universidad de Costa Rica. Sobre este inmueble y sus particularidades diseñaremos un sistema de audio en audífonos para nuestro montaje ficticio de Hamlet. ¡Que comience la función!

profesional para los discos compactos y, luego, para los archivos de audio de transmisión en internet. Esta frecuencia es el resultado del teorema de Nyquist, el cual está fuera del objeto del estudio de este documento. Sin embargo, el lector puede referirse al capítulo 35: DSP Technology del libro Hand-book of Sound Engineer (ver referencias) en el cual podrá encontrar información altamente detallada detrás de las matemáticas y técnicas de muestreo digital.

ESCENA. Revista de las artes, 2019, Vol. 79, Núm. 1 (julio-diciembre), pp. 145-176 


\section{El Teatro Universitario presenta... Hamlet (sala teatral $\rightarrow$ actores/micrófonos)}

Sean inalámbricos o no, los audífonos ofrecen un aislamiento del entorno acústico, fenómeno descrito como el "fenómeno walkman". Hosokawa describe cómo el walkman de Sony introdujo, no solo la portabilidad del sonido y su control, sino también, una especie de "teatro secreto" o "teatro de audífonos" (citado en Klich, 2017, p. 366). Para lograr este "teatro secreto" con audífonos, debemos captar las voces de los actores en tiempo real a través de micrófonos y esta captura, a su vez, debe ser enviada a los audífonos de la audiencia. Antes, definiremos algunos parámetros en cuanto a las fuentes sonoras de nuestro espectáculo Hamlet:

- La capacidad de público máxima recomendada para el Teatro Universitario, que será el teatro que utilizaremos como referencia, es 96 espectadores. Por eso, el diseño contempla esta cantidad de personas.

- La fuente más importante de captación y envío es el diálogo entre los actores y actrices. Esta se podría realizar por medio de micrófonos, que capturan el sonido de forma distinta: monoaurales de solapa inalámbricos (para una mezcla estéreo), o binaural (para una mezcla binaural). Es posible combinar ambos tipos de micrófono.

- La música del espectáculo será previamente producida y, luego, reproducida en el espectáculo. No ejecutada en vivo.

- Los efectos sonoros, salvo aquellos producidos por las acciones de los personajes en el escenario de forma natural, serán previamente producidos y luego, reproducidos en el espectáculo.

- Los ambientes sonoros serán previamente producidos y, luego, reproducidos en el espectáculo.

- Todas las fuentes sonoras producidas y preproducidas del espectáculo serán enviadas a la mesa mezcladora, desde la cual, se transmitirá una única mezcla de forma inalámbrica a todos los audífonos de la audiencia.

- Se ubicarán altavoces en posiciones estratégicas, dentro del escenario, para dotar al elenco de referencia de los pies de sonido presentes en el espectáculo. El volumen de estos altavoces deberá ser cuidadosamente ajustado para que no se filtre en los micrófonos de los actores ni del escenario y cree un "eco" en la mezcla de los audífonos de la audiencia. 
Audífonos inalámbricos para un espectáculo teatral en Costa Rica:

Artículos diseño de sistema para 96 espectadores

Al definir los parámetros anteriores, en este documento, exploraremos los micrófonos mono canal inalámbricos de solapa convencionales y un micrófono binaural: el Neumann $\mathrm{KU}-100$. Antes de decidirse por uno u otro micrófono, es importante analizar el espacio en donde tomará lugar el hecho teatral en cuestión. Con esto, nos referimos a la capacidad del edificio teatral de no permitir el ingreso de ruidos exteriores. De modo sencillo, podemos definir el ruido como aquellos sonidos que no nos interesa escuchar, frente a la señal, que son aquellos sonidos que sí queremos escuchar. En nuestro caso, ruidos externos son: motocicletas pasando por la calle, bocinas de distintos automotores, aviones y helicópteros pasando, pitoretas del tren urbano o conversaciones de los transeúntes. Otra manera de ver el ruido es como aquel sonido que no pertenece al mundo de la representación en escena. Si para nosotros, la historia del príncipe Hamlet sucede en un castillo medieval, ninguno de los ruidos exteriores, antes mencionados, encaja en nuestro mundo sonoro medieval, por consiguiente, distraerá a la audiencia.

Así mismo, ruidos generados por los sistemas de enfriamiento de las luminarias móviles, máquinas de humo, pasos o conversaciones tras bambalinas o zumbidos eléctricos emitidos por los altavoces producto de cables dañados o no balanceados, son el tipo de ruidos internos que queremos eliminar o enmascarar. Hablando, específicamente, del Teatro Universitario (TU), el inmueble presenta serios problemas de aislamiento acústico. De los ruidos exteriores antes mencionados, la mayoría ingresa con muy poca atenuación y, por supuesto, lo mismo sucede a la inversa: los sonidos generados dentro de la sala salen sin atenuación. Reconocer este problema resulta muy sencillo: basta con que suene la corneta del tren interurbano de las 5:00 p.m. (el TU está ubicado a unos 400 metros de la estación más cercana) o que pase una motocicleta con una mufla alterada por la calle que está frente al teatro, para entender que, cualquier ruido externo implica filtración interna. Desde luego, estos ruidos interrumpen y distraen a los espectadores del espectáculo porque no pertenecen al mundo ni los sucesos de la obra y acontecen de forma aleatoria. Lo cierto es que los micrófonos que usemos para captar las voces de los actores también van a captar estos ruidos intrusivos en mayor o menor medida. Entonces, para una mezcla convencional estéreo en nuestro hipotético montaje de Hamlet en el T.U., optaríamos por usar micrófonos inalámbricos de solapa o "lavalier", utilizando la técnica propia de los musicales: el micrófono lo más cerca de la boca del actor o actriz. En contraste con la técnica del cine, que sería en el pecho. La técnica del musical asegura una mejor "relación señal/ruido", lo que significa que tendremos más presente la voz del intérprete

4 Relación señal/ruido, o signal to noise ratio en inglés, es un parámetro técnico que explica cuanto ruido genera inherentemente un dispositivo debido a sus componentes. Todo aparato genera ruido como parte de la energía que se disipa como calor y el valor de esta relación es que el ruido sea muy poco en comparación de la señal captada. El término también aplica cuando se utiliza un

ESCENA. Revista de las artes, 2019, Vol. 79, Núm. 1 (julio-diciembre), pp. 145-176 
a expensas de que suene menos "natural" y que el micrófono sea mínimamente visible a la distancia. Usualmente, cada actor tendría un micrófono dedicado para su voz y esto significaría un canal de sonido dedicado en la mesa de mezcla, es decir, micrófono 1 al canal 1 y, así, sucesivamente. La práctica usual en la mezcla estéreo es mantener las fuentes sonoras de mayor peso ubicadas en el centro de la imagen estéreo. O sea, 0\% izquierda/derecha. Como ejemplo, podemos citar casi cualquier canción comercial: la voz del o la vocalista estará ubicada en el medio de los dos audífonos para mantener su protagonismo a lo largo de la canción.

Para muchos sonidistas, los micrófonos de solapa son complejos de manejar en actuaciones en vivo, porque tienden a generar mucha retroalimentación, o feedback, (ese chillido que se escucha cuando un micrófono se acerca o está cerca de un parlante) debido a su patrón polar omnidireccional ${ }^{5}$. Al realizar los cálculos correctos de PAGNAG ${ }^{6}$ y ajustar la posición e inclinación de los altavoces en un sistema, la retroalimentación se puede hasta eliminar (Sigismondi, 2015, p. 1496). Como nuestro montaje se transmite a través de audífonos, el PAGNAG aumenta considerablemente, por lo que la retroalimentación ya no sería un problema. Es por esto que, los micrófonos de solapa se proyectan como una buena opción. Recordemos que el objetivo es entregar una muy buena relación señal/ruido, teniendo en cuenta que nuestro teatro permite el ingreso de sonidos intrusivos con mucha facilidad. Entonces, señal es todo lo que me interesa capturar (como la voz de la actriz) y ruido es todo lo que me interesa atenuar o enmascarar con la señal (como la corneta del tren).

micrófono (y asumiendo) con una excepcional relación señal/ruido para capturar una fuente sonora, el ruido se considera para todos aquellos sonidos distintos de la fuente. Por ejemplo, si nuestra intención es capturar el sonido del tambor (señal) de una batería, el resto de los instrumentos (bombo, platos, hi-hat, golpes no intencionales de baquetas, sonidos generados por el baterista como la respiración) se vuelven ruido. La meta es capturar la señal del tambor con una amplitud de onda o volumen muy alto y el resto de la batería y ruidos antes mencionados con baja amplitud o bajo volumen. Las formas en que se puede aislar una señal del ruido dependen mucho del tipo de micrófono y su patrón polar, así como la distancia entre el micrófono y la fuente y, desde luego, el volumen mismo de la fuente.

${ }^{5}$ Los micrófonos se pueden clasificar según la forma en captan el sonido. Los micrófonos omnidireccionales (incluidos los binaurales) captan sonido de forma esférica, de todas las direcciones. Por el contrario, el micrófono de mano convencional, como el de los karaokes, es un micrófono de patrón cardiode, o de corazón, y su recepción es efectiva hablando directo al micrófono.

6 PAG: Potential Acoustic Gain / NAG: Needed Acoustic Gain, por sus siglas en inglés. Operación matemática que permite estimar si un sistema tiene el suficiente rango dinámico para emitir sonido amplificado antes de generar retroalimentación. Entre más grande sea la relación de PAG con respecto a NAG, mayor podrá ser la ganancia que se le puede dar a un micrófono sin retroalimentar el sistema.

ESCENA. Revista de las artes, 2019, Vol. 79, Núm. 1 (julio-diciembre), pp. 145-176 
Audífonos inalámbricos para un espectáculo teatral en Costa Rica:

Artículos diseño de sistema para 96 espectadores

Ahora, si nuestro hipotético montaje de Hamlet sucede en un hipotético T.U. acústicamente aislado, en donde los ruidos intrusivos no sean un problema, exploraríamos la opción del sonido binaural colocando un micrófono binaural como el Neumann KU-100 (Neumann, 2018) en el centro del escenario. Estos micrófonos captan omnidireccionalmente los sonidos, pero lo hacen utilizando un método distinto. El KU-100 se conforma de dos micrófonos incrustados en los canales auditivos de la cabeza de un maniquí que, incluso, exhibe orejas. Esta cabeza que tiene concavidades como las que tendría una cabeza humana real, permite acercar la captación de los sonidos a la forma en la que nuestros oídos humanos lo hacen. La forma de las orejas, los canales auditivos, las zonas huecas y el tamaño de la cabeza es lo que hace que nosotros podamos percibir sonidos arriba, abajo, adelante y atrás. Al ubicar un micrófono binaural en el centro del escenario, se recrea en los audífonos el mismo entorno sonoro del escenario en el cual están actuando los personajes. El sonido estéreo, por el contrario, se escucha en los audífonos en un arco bidimensional de $180^{\circ}$ (izquierda, centro y derecha) y la profundidad se puede crear o acentuar utilizando reverberaciones, lo cual carece de la sensación realista de profundidad y localización que genera el sonido binaural. Cabe señalar que las capturas y grabaciones de sonido binaural se trasladan muy bien en los audífonos, pero pierden su efecto tridimensional cuando se reproducen en los altavoces. ¿Cuál sería entonces el valor de este tipo de micrófonos en un espectáculo? Existe en YouTube una serie de videos que, en realidad, son como pequeños radioteatros hechos con micrófonos binaurales, su mayor valor reside en exhibir la sensación de realidad espacial auditiva que estos producen. Uno de los más comunes es el de la barbería, en donde un barbero italiano corta el pelo al cliente (en este caso usted, como escucha), mientras un amigo del barbero toca la guitarra. Aún con los ojos cerrados, el cerebro es capaz de precisar la ubicación y distancia de cada una de las fuentes. Invito al lector a escuchar una de estas grabaciones para que ilustre mejor lo que viene a continuación.

El objetivo de los audífonos es sumergir a la audiencia en la historia que se presenta en escena. Utilizando un único micrófono binaural, ubicado en el centro del escenario, que capture los diálogos, pasos y sonidos generados por los actores en la escena, se ubica auditivamente al espectador en el centro de la escena, generando un espacio circular. Es como si sentáramos al espectador en el centro del escenario y el elenco actuara directamente para él o ella. Un buen ejemplo es el video en YouTube: Virtual reality for your ears (BBC Click, 2016). A partir del minuto 4:52, el lector podrá tener una idea más clara de cómo se percibe el audio binaural y de cómo luce el micrófono Neumann KU-100. Además, de por qué la disposición en el centro del escenario es la óptima para la captación de los diálogos y acciones en escena. Desde luego, se podría argumentar que dos micrófonos convencionales idénticos dispuestos para capturar en estéreo pueden generar el mismo efecto. Pero, como comentaba anteriormente, las técnicas de captación son distintas y ambas arrojan distintos resultados a nivel espacial de los sonidos.

ESCENA. Revista de las artes, 2019, Vol. 79, Núm. 1 (julio-diciembre), pp. 145-176 
Es necesario enfatizar que todos los diálogos captados serán enviados a la mesa de mezcla, independientemente, de que los micrófonos sean binaurales, mono (un solo canal) o estéreo. También es necesario aclarar que no se hace especial recomendación sobre uno u otro formato, sino, explicar, simplemente, las diferencias entre ellos y que ambos formatos son igualmente válidos y funcionales e inclusive, combinables. Además, el éxito de la experiencia sonora no solo depende de los micrófonos y su ubicación, sino que la mesa de mezcla (y desde luego, la persona que opera la mesa) juega un rol fundamental en la distribución de los sonidos, tanto en volumen como en espacio. Sumado a que la mesa podría o no grabar el sonido del espectáculo, pero no es un requisito. Resumiendo, si el espectáculo se hace con micrófonos inalámbricos de solapa convencionales:

- Se necesita un micrófono por cada miembro del elenco, lo cual aumenta la inteligibilidad de los actores, porque la proximidad entre micrófono e intérprete es constante.

- Funcionaría mejor para un espectáculo a la italiana o de un solo frente.

- Cada micrófono ocupará un canal individual en la mesa de mezcla.

- El micrófono captará en mayor medida la voz de los y las intérpretes y, en menor medida, la acústica y ruidos internos y externos al momento de la captura.

- Las voces se mantendrán ubicadas en el centro del espectro estéreo de los audífonos de la audiencia, la mayor parte del tiempo. A menos que, manualmente, se disponga de otra ubicación para un efecto específico.

- Para agregar espacialidad y profundidad a los micrófonos de los actores, se puede optar por ubicar dos micrófonos en el centro del escenario, en el centro de la sala teatral, o en ambas y agregar estos canales a la mezcla de audífonos. Si se agregan micrófonos en el centro del escenario, estos deben ser enmascarados o camuflados con la escenografía para no atraer la atención sobre ellos, a menos que el diseñador de sonido y el director acuerden su exposición como parte de la plástica visual del espectáculo.

Si el espectáculo se realiza con un micrófono binaural:

- Se necesita un micrófono para captar a todo el elenco. Sin embargo, hay que considerar que hablar a una distancia alejada del micrófono reduce la inteligibilidad de la palabra de los actores.

- Funcionaría mejor para un espectáculo de tres frentes, semi-circular, o en donde los actores den la espalda al público, sin que esto sea un inconveniente. 
Audífonos inalámbricos para un espectáculo teatral en Costa Rica:

- El micrófono ocupará dos canales en la mesa de mezcla, los cuales deberán ser ajustados 100\% derecha y $100 \%$ izquierda, respectivamente.

- El micrófono captará en mayor medida todos los sonidos generados en el escenario incluida su acústica y, en menor medida, los sonidos de la audiencia y el teatro mismo.

- Existirá correspondencia espacial vertical y horizontal entre las voces de los actores y la emitida en los audífonos, sin necesidad de agregar más micrófonos o hacer ajustes manuales. Además de dar una sensación muy realista de audición.

- Si se agrega este micrófono en el centro del escenario, este debe ser enmascarado o camuflado con la escenografía para no atraer la atención sobre él, a menos que el diseñador de sonido y el director acuerden su exposición como parte de la plástica visual del espectáculo.

Hablando un poco de la inversión económica, el micrófono binaural Neumann KU100 (aunque costoso: \$8000), representaría una buena alternativa en un supuesto elenco de veinte actores y actrices, puesto que un solo micrófono resuelve la captación y la localización espacial. Versus 20 sistemas de micrófonos inalámbricos convencionales individuales. Cada sistema de micrófono inalámbrico que se compone de: micrófono, transmisor inalámbrico, baterías recargables y receptor alámbrico tiene un valor aproximado de $\$ 800$. Esto nos da como resultado unos \$16000 en micrófonos inalámbricos. De existir el presupuesto, la combinación de ambos tipos de micrófonos incluso expandiría las capacidades creativas del diseñador sonoro. Por ejemplo, se puede utilizar el micrófono binaural para las escenas en las que están varios personajes y de existir un aparte, en esa misma escena, se podría encender solo el micrófono inalámbrico del personaje que interpreta el aparte, para darle mayor protagonismo.

Para finalizar este apartado, es necesario recordar que el éxito del sonido binaural depende mucho de cuantos ruidos indeseables entran en el recinto. Incluso, hay que considerar los generados por los propios aparatos del teatro, como los sistemas de luces o tramoya, por ejemplo. El sonido binaural representa una propuesta más "realista y tridimensional”. Mientras que, los micrófonos de solapa ofrecen mejor relación señal-ruido y definición de los diálogos a expensas de tener un sonido más plano y "menos" tridimensional. 


\section{Mientras tanto, en el Front of House... (reproducción de fuentes sonoras en computadora $\rightarrow$ mesa de mezcla)}

Recibimos desde los micrófonos la señal que hemos de mezclar con otros elementos en el Front of House $(\mathrm{FOH})^{7}$. Allí, encontramos a los operadores de sonido e ingenieros que mezclan las fuentes y los sonidos concebidos por el diseñador de sonido, y la tecnología alámbrica e inalámbrica que hace posible la transmisión a los audífonos. Seguidamente, hablaremos de la mesa mezcladora Behringer X32, el computador Apple iMac que, específicamente, tiene instalado el programa Qlab $3^{8}$ y de los componentes inalámbricos que permitirán enviar la mezcla hasta los audífonos de la audiencia.

La Behringer X32 es una mesa mezcladora digital con 32 entradas, que pueden ser asignadas como análogas o digitales, 6 entradas auxiliares, 16 salidas análogas, 2 salidas de monitor, 32 salidas directas digitales USB y 6 salidas auxiliares. Esta mesa, sin duda, permite manejar una gran cantidad de fuentes sonoras y enviarlas a los canales estéreo necesarios para los audífonos. La computadora Apple iMac, que corre el programa Qlab 3 , se comunica por USB con la mesa X32. En la mesa es posible asignar hasta 32 canales de audio independientes de Qlab 3. En un diseño de sonido hecho por altavoces es

7 Traducido como "frente de escena", es el lugar dentro de la platea o área de butacas en la que se encuentra el ingeniero de mezcla y, desde luego, la mesa mezcladora. Tradicionalmente, se la ubica en el punto medio de dos sistemas de altavoces que usualmente son izquierdo y derecho. Aunque para nuestro tipo de mezcla la ubicación del FOH no es tan relevante, para los espectáculos en vivo con altavoces o conciertos, su posición es crucial. Existe la tradición en Costa Rica de que los FOH están ubicados dentro de cabinas de control. Estas cabinas no solo representan una distorsión del sonido que realmente llega a la audiencia debido a que el ingeniero de mezcla u operador compensa las deficiencias sonoras de su entorno afectando el sonido que realmente escuchan los espectadores en el teatro, sino también porque las cabinas suelen contener aparatos del sistema lumínico que generan ruido por los abanicos de enfriamiento. Este factor desde luego dificulta la labor de mezclar correctamente los niveles y balance tonal de los distintos sonidos y música presentes en un espectáculo.

8 Qlab 3 es un programa para el control de espectáculos en vivo y es exclusivo del sistema operativo Apple MacOS. El programa puede controlar audio, micrófonos, cámaras, videos y enviar señales MIDI para dar comandos a otros dispositivos de forma remota. Específicamente en audio, Qlab 3 se diferencia de programas de grabación de audio como Pro-Tools en que Qlab 3 solo reproduce, no graba ni crea sonidos. Qlab 3 busca archivos de audio dentro del computador y permite reproducirlos de forma simultánea, cada uno con su propio nivel de volumen, panoramización, efectos, fundidos entre otras funcionas. El diseñador de sonido programa cada uno de los pies de sonido según las necesidades del espectáculo. Para más información el lector puede visitar el sitio www.figure53.com

ESCENA. Revista de las artes, 2019, Vol. 79, Núm. 1 (julio-diciembre), pp. 145-176 
deseable asignar un canal de salida Qlab 3 por altavoz. Pero, en este caso, se necesitaría un canal estéreo para toda la mezcla. Entonces, si necesitáramos conectar 20 micrófonos (de los actores en escena) a la mesa, asignaríamos las entradas del 1 al 24 como análogas (la asignación análoga-tarjeta se puede hacer en bancos de 8 entradas). Mientras que, las entradas del 25 al 32 serían digitales o "tarjeta". Como Qlab 3 permite control individual de volúmenes de cada uno de los archivos de audio importados a la sesión de trabajo, no es necesario tener más de dos canales asignados en la X32 para recibir toda la mezcla desde Qlab 3. Así que los canales 25-26 sería más que suficiente, asumiendo que el espectáculo no tiene música en vivo. De lo contrario, nos quedarían 4 canales libres, del 21 al 24, para agregar instrumentos musicales de ser necesarios. La figura 1 (diagrama de flujo) muestra como fluye la señal desde los micrófonos hasta los audífonos inalámbricos del público.

La pregunta que sigue es, ¿cómo hacemos para entregar sonido a 96 audífonos? Se entiende, entonces, que la mesa de mezcla Behringer X32 recibe las señales inalámbricas de los micrófonos de solapa o la señal por cable de audio del micrófono binaural y las combina con los sonidos reproducidos desde Qlab 3. Esto para enviarlos mezclados hacia los transmisores conectados a las salidas de la mesa. A su vez, estos envían la señal inalámbrica hacia los audífonos de los espectadores. Del total de salidas estéreo que nos ofrece la mesa de mezcla X32, nos bastan dos para alimentar 96 audífonos al mismo tiempo, sea la mezcla estéreo o binaural (esto porque ambos utilizan dos canales para la captación y reproducción. Lo que difiere es su método de captura). Pasemos ahora, a comentar sobre los sistemas IEM que servirán como transmisores y receptores de nuestros audífonos inalámbricos.

\section{Hamlet te habla al oído: alimentando 96 audífonos (transmisores IEM)}

La señal de audio que contiene toda la mezcla sale de Out 1-2 en la mesa y conecta al transmisor fijo \#1. Para la transmisión inalámbrica utilizaremos los sistemas in ear monitoring, o monitores personales que, frecuentemente, utilizan los músicos para escucharse en escena durante sus actuaciones en vivo. Si usted ha visto conciertos de su artista favorito en DVD o canales de música y ha notado que usan una especie de audífonos mientras tocan o cantan, pues, entonces, usted ha visto un sistema IEM, específicamente, el audífono conectado al receptor inalámbrico. Los sistemas IEM se componen de transmisor (usualmente fijo y conectado por cable a alguna fuente) y un receptor (usualmente inalámbrico y alimentado por baterías). Estos sistemas permiten que todos los músicos en el escenario escuchen una mezcla dedicada a sus necesidades particulares; distinta de la que escucha la audiencia a través de los altavoces, de forma inalámbrica y con la capacidad de controlar el volumen. Pero, estos sistemas no se quedan ahí con una mezcla colectiva, porque añaden versatilidad para atender a cada músico de forma independiente e individual, si se 
incorporan varios transmisores en distintas frecuencias: una para cada uno. En nuestro caso, aprovecharemos la capacidad de transmitir una mezcla a todos los espectadores de nuestro espectáculo, asegurándonos uniformidad de volumen, espacial y tonal, como si sintonizáramos una estación de radio.

Como mencioné anteriormente, utilizaremos dos salidas estéreo disponibles de la X32 para enviar la señal capturada desde los micrófonos de vuelta a los 96 audífonos. En una de ellas estará conectada un transmisor sintonizado a una frecuencia. En la otra salida, el segundo transmisor estará sintonizado en la misma frecuencia que el anterior y servirá como equipo de respaldo en caso de que el transmisor \#1 fallara. De este modo, basta con encender el transmisor \#2 para reestablecer la comunicación entre el transmisor y los receptores nuevamente. Para mayor claridad, conectaremos los transmisores estéreo a las salidas Out 1-2 y Out 3-4 de la X32. Los 96 receptores inalámbricos (a los que conectaremos los audífonos) se sintonizarán a la frecuencia del transmisor. Esto dará como resultado que un transmisor alimente 96 (o más) receptores IEM de forma simultánea. Según el fabricante de Shure, el número que receptores IEM que se puede conectar a un transmisor es "ilimitado" (Shure America, 2018). Por otro lado, el fabricante Sennheiser declara que es posible sintonizar "múltiples receptores a un mismo transmisor", pero no precisa una cantidad (Sennheiser, 2018). Consultado sobre este tema, el profesor Guillermo Rivero de la Universidad de Costa Rica, especialista en radiofrecuencias y consultor del Instituto Costarricense de Electricidad (ICE) nos dice:

Este sistema (Shure PSM 900 y Sennheiser IEM G4) tiene la posibilidad de 9 rangos de frecuencia de operación, cada rango es de $42 \mathrm{MHz}$ de ancho de banda y cada receptor tiene un ancho de banda de $25 \mathrm{khz}$, por lo cual permite la conexión de 1680 dispositivos por sintetización de frecuencia (comunicación personal con Rivero, 2018).

Sigismondi (2015) refuerza la afirmación de Rivero indicando que "with a wireless personal monitor system, however, the number of receivers monitoring that same mix is unlimited. Additional receivers do not load the transmitter, so feel free to add as many receivers as necessary without adding more transmitters [con un sistema de monitoreo personal inalámbrico, el número de receptores escuchando la misma mezcla es ilimitado. Agregar receptores no carga el transmisor, así que puede sentirse libre de agregar tantos receptores como usted desee, sin necesidad de transmisores adicionales]" (p. 1498).

En Costa Rica, se puede lograr el objetivo de transmitir el audio a 96 audífonos, ya sea con los sistemas IEM del fabricante Shure o Sennheiser, ambos con representación en el país. Como ya quedó explicado arriba, para cada sistema IEM necesitaremos dos transmisores y 96 receptores.Para el sistema IEM de Shure necesitaremos: 2 transmisores 
Audífonos inalámbricos para un espectáculo teatral en Costa Rica:

estéreo modelo P9T, 96 receptores modelo P9RA, 244 baterías recargables AA de 2500 $m A^{9}$ (192 baterías para alimentar todos los receptores y, al menos, una 1/4 parte extra como repuesto) y los audífonos que se conectan al receptor, a través de un conector estándar de $3.5 \mathrm{~mm}^{10}$. Si el diseñador de sonido opta por el fabricante Sennheiser, los dispositivos necesarios serían: 2 transmisores modelo SR IEM G4, 96 receptores modelo EK IEM G4, igual cantidad de baterías AA de 2500 mA y, desde luego, los 96 audífonos.

El espectador recibirá dos componentes: el receptor inalámbrico y los audífonos. El receptor deberá colgarse de la pretina del pantalón o falda, preferiblemente. Al ser un sistema de monitoreo profesional, estos están concebidos para ajustarse sobre el vuelo, lo que supondría un problema para el diseñador y los operadores, puesto que los controles y la configuración del dispositivo mismo pueden estar en riesgo con aquellos miembros de la audiencia con manos "curiosas". Afortunadamente, los receptores IEM permiten bloquear la operación de todo el aparato, incluso la perilla del volumen. Quizás algunos espectadores agradezcan el hecho de controlar ellos mismos el volumen de salida de los audífonos, aunque es deber del diseñador establecer el nivel de salida estándar para el espectáculo, el cual recomendamos que sea 85 dB SPL, ponderación A en cada uno de los audífonos. Este nivel debe estar marcado en el punto donde la perilla emite el volumen deseado, para que el usuario regrese rápidamente al nivel preestablecido. La tabla 1 resume mejor la forma en que la señal será transmitida desde la mesa a los audífonos.

Tabla 1. Conexión de salidas X32 a transmisores estéreo

\begin{tabular}{|c|l|l|}
\hline Salida Estéreo Mesa X32 & Transmisor Estéreo & Receptores/Audífonos \\
\hline Out 1-2 & T1 & $1-96$ \\
\hline Out 3-4 (Repuesto) & T2 (Repuesto) & $1-96$ \\
\hline
\end{tabular}

Fuente: Elaboración propia.

De esta manera, podremos transmitir todo el audio capturado a través de los micrófonos y sonido reproducido desde Qlab 3 y aquellos instrumentos musicales que estuvieren conectados a la mesa, directamente a los audífonos de una forma inalámbrica. Ahora que ya hemos creado un sistema, nos queda hablar del último componente de nuestro sistema inalámbrico: el audífono.

\footnotetext{
${ }^{9} \mathrm{~mA}$ : miliamperios.

${ }^{10} \mathrm{~mm}$ : milímetros.
}

ESCENA. Revista de las artes, 2019, Vol. 79, Núm. 1 (julio-diciembre), pp. 145-176 


\section{Algunas consideraciones técnicas para elegir los audífonos para Hamlet}

La primera consideración es de carácter higiénico. Como se mencionó anteriormente, en Costa Rica se puede conseguir los receptores inalámbricos Sennheiser EK IEM G4 o Shure P9RA, los cuales incluyen un par de audífonos "de pastilla" o earbuds como parte de la compra. Pero, el hecho de que estos deban ser introducidos en el oído los vuelven poco atractivos para nuestro espectáculo. Se debe considerar que vamos a prestar audífonos de meter en el oído a muchos espectadores en una temporada de funciones de no menos de cuatro semanas. No solo es una tarea compleja eliminar la cera de oído de 96 pares de audífonos al final de cada función, sino que, a algunos de los espectadores les parecerá desagradable utilizar audífonos que han sido introducidos en los oídos de otra persona. Podríamos argumentar que cada espectador pueda usar sus audífonos personales para evitarse situaciones incómodas. Pero, parte de diseñar la experiencia sonora de un espectáculo es garantizar uniformidad del sonido y eso implica tener control y conocimiento de los dispositivos involucrados en el proceso. Por eso, debemos considerar un par de audífonos que sean fáciles de poner, quitar, limpiar y que, desde luego, suenen bien. Entendiendo que ahora debemos poner atención a ciertas especificaciones, para hacer la mejor elección.

La segunda tiene que ver con la impedancia. La impedancia (la cual se mide en ohmnios y se representa con la letra griega omega: $\Omega$ ) es una fuerza en oposición a la corriente que pasa por un circuito, cuando se aplica un voltaje. Como regla general y muy simple en los audífonos, entre menor sea la impedancia del preamplificador en relación con la impedancia de los audífonos, menor será la corriente que circula por el circuito, por tanto, mayor será el volumen percibido por el oyente. Esta regla puede expresarse como una relación de 1/8. Es decir, el preamplificador tiene una impedancia de la octava parte de la impedancia de los audífonos (Engstrom, 2013). Cualquiera de los receptores inalámbricos (Shure o Sennheiser) antes mencionados tiene impedancia de salida de $32 \Omega$, por lo que, un audífono ideal debería ser de $256 \Omega$, de acuerdo con el enunciado anterior. Por otro lado, la teoría detrás de los circuitos indica que igualar impedancias supone una maximización de la energía eléctrica que se transmite a las bocinas de los audífonos y, por consiguiente, un sonido sin distorsión a un volumen definido, que no está exento de pérdida de poder (Shure America, 2016). No obstante, las dos aproximaciones para empatar las impedancias, descritas arriba, casi nunca se cumplen al pie de la letra, debido a la gran oferta de dispositivos de audio profesional y del consumo con distintos diseños de circuitos que resultan en diversas impedancias. Este hecho impacta el sonido de nuestro espectáculo de la siguiente manera: suponga que un audífono A tiene $38 \Omega$, mientras que un audífono B tiene $55 \Omega$. Cada uno de estos audífonos será conectado a un receptor IEM que tiene $32 \Omega$. La perilla que controla el volumen en el receptor IEM se coloca a la mitad de su giro total, es decir, a las 12 en punto. Si se reproduce el mismo sonido a través de cada uno de los audífonos y se mide con 
un sonómetro notará que el audífono $B$ emitirá un nivel levemente más bajo que el $A$, esto debido a la mayor impedancia de $\mathrm{B}$, y necesitará un poquito más de vuelta en la perilla para equipar su nivel de volumen con el audífono $\mathrm{A}$. Esto no debe interpretarse jamás como una ventaja del audífono $\mathrm{A}$ sobre el $\mathrm{B}$, sino como una condición a tomar en cuenta cuando se decida el volumen promedio al que sonará el espectáculo en su totalidad.

Como tercera especificación tenemos la sensibilidad. Al igual que en los altavoces, mayor sensibilidad significa mayor capacidad de manejar altas presiones sonoras sin distorsionar o incluso, dañar las bocinas. Este parámetro se mide como " $\mathrm{n}$ " decibelios ${ }^{11}$ de presión sonora o SPL ${ }^{12}$ equivalen a $1 \mathrm{~mW}^{13}$. Tomemos por ejemplo el audífono AKG K240 Studio. Su sensibilidad está especificada como 104 dB SPL a 200 mW. Es decir, cuando la potencia en watts del dispositivo que alimenta el audífono llegue a los $200 \mathrm{~mW}$, el audífono podrá producir los $104 \mathrm{~dB}$ de presión sonora, pero estaremos llevando al audífono a sus límites. Lo anterior nos hace saber que este audífono podrá generar este nivel por un periodo muy corto de tiempo o, mejor dicho, en un pico de volumen. También, que llevar al audífono a este nivel, de forma constante lo sobrecargará. Por otro lado, si miramos las especificaciones de los receptores IEM Shure P9RA notaremos que es capaz de generar 200 $\mathrm{mW}$ de salida. Si conectamos el audífono AKG 240 Studio a este receptor y calibramos su perilla de volumen para que el nivel de salida constante sea $85 \mathrm{~dB}$ SPL, obtendremos como resultado que el receptor necesita generar $22 \mathrm{~mW}^{14}$. Vemos, entonces, que el receptor inalámbrico puede, en teoría, suministrar el suficiente poder para hacer funcionar correctamente el audífono. También apreciamos que conforme bajamos el volumen, la demanda de poder desciende de forma exponencial.

${ }^{11}$ Decibelio, o dB, es la décima parte de un Belio y expresa una relación entre cantidades. Cabe resaltar que el decibelio no es una unidad de medición, sino el cambio exponencial de la energía. Por ejemplo, un cambio de 20 dB significa que la intensidad aumentó 100 veces, puesto que el 2 de los decimales en realidad es 10 elevado a la "n" potencia de los decimales, que en este caso es 2.

${ }^{12}$ Sound pressure level o nivel de presión sonora por sus siglas en inglés. Medida de intensidad de volumen del sonido que se puede calcular a partir de la presión atmosférica. Por ejemplo, 0 dB SPL, o el umbral de la audición humana, equivalen a 0.00002 Pascales, y el Pascal considera la presión que ejerce la atmósfera terrestre metros cuadrados.

${ }^{13} \mathrm{~mW}$ : miliwatt o la milésima parte de $1 \mathrm{~W}$, o Watt.

${ }^{14}$ Estos datos fueron obtenidos y comparados con distintas calculadoras de preamplificadores para audífonos. La compañía Shure ofrece las ecuaciones en las que se basan estas calculadoras. Dada su practicidad, las calculadoras utilizadas en este documento se pueden consultar en: http://auditry.blogspot.com/2014/02/headphone-amp-power-calculator.html y en: http:/www. digizoid.com/headphones-power.html.

ESCENA. Revista de las artes, 2019, Vol. 79, Núm. 1 (julio-diciembre), pp. 145-176 
La cuarta especificación por considerar en la selección de los audífonos es la respuesta de frecuencia y se define a través de una gráfica que muestra la capacidad del dispositivo para reproducir las frecuencias audibles del ser humano. Este tipo de gráficas se utilizan, sobre todo, para ilustrar cómo capta el sonido un micrófono o cómo lo reproduce un altavoz o un audífono. De forma muy rápida, el usuario puede saber si el dispositivo acentúa algunas frecuencias más que otras. Incluso, entre los audífonos de consumo comercial es posible encontrar este tipo de gráficas. Lo que usualmente separa a los equipos de consumo de los profesionales es que los últimos apuntan a tener una respuesta de frecuencias "plana". El término "plano" quiere decir que ninguna de las frecuencias o bandas de frecuencias que el audífono es capaz de producir está aumentada o disminuida. Esto frente a los audífonos de consumo en donde la meta es, más bien, preestablecer curvas de respuesta que acentúen y disminuyan ciertas frecuencias para producir un sonido placentero. La principal razón por la que el audio profesional necesita y aspira ser lo más plano posible es la escucha crítica, en la cual el sonido es evaluado para detectar sus imperfecciones y poder corregirlo. Al tener curvas de respuesta predeterminadas para la escucha placentera, los equipos de consumo fallan como dispositivos de escucha crítica, porque enmascaran sonidos o frecuencias indeseables y ofrecen una imagen sonora distorsionada de lo que realmente está sonando. No obstante, la propia física que involucra el fenómeno de la dispersión sonora, así como las verdaderas capacidades prácticas de los circuitos y componentes alejan a los equipos de audio profesional de la ansiada línea recta plana, que se espera ver en una gráfica de respuesta de frecuencia. Ante esta realidad, es aceptado que una desviación de $+/$ - 3dB se considera plano, $+/$ - $6 \mathrm{~dB}$ aceptable, y mayor que estos valores como aumentos o atenuaciones de las frecuencias en cuestión. La figura 1 muestra la respuesta de frecuencia del audífono AKG K240 Studio. 
Audífonos inalámbricos para un espectáculo teatral en Costa Rica: diseño de sistema para 96 espectadores

Figura 1. Respuesta de frecuencia del audífono AKG K240 Studio

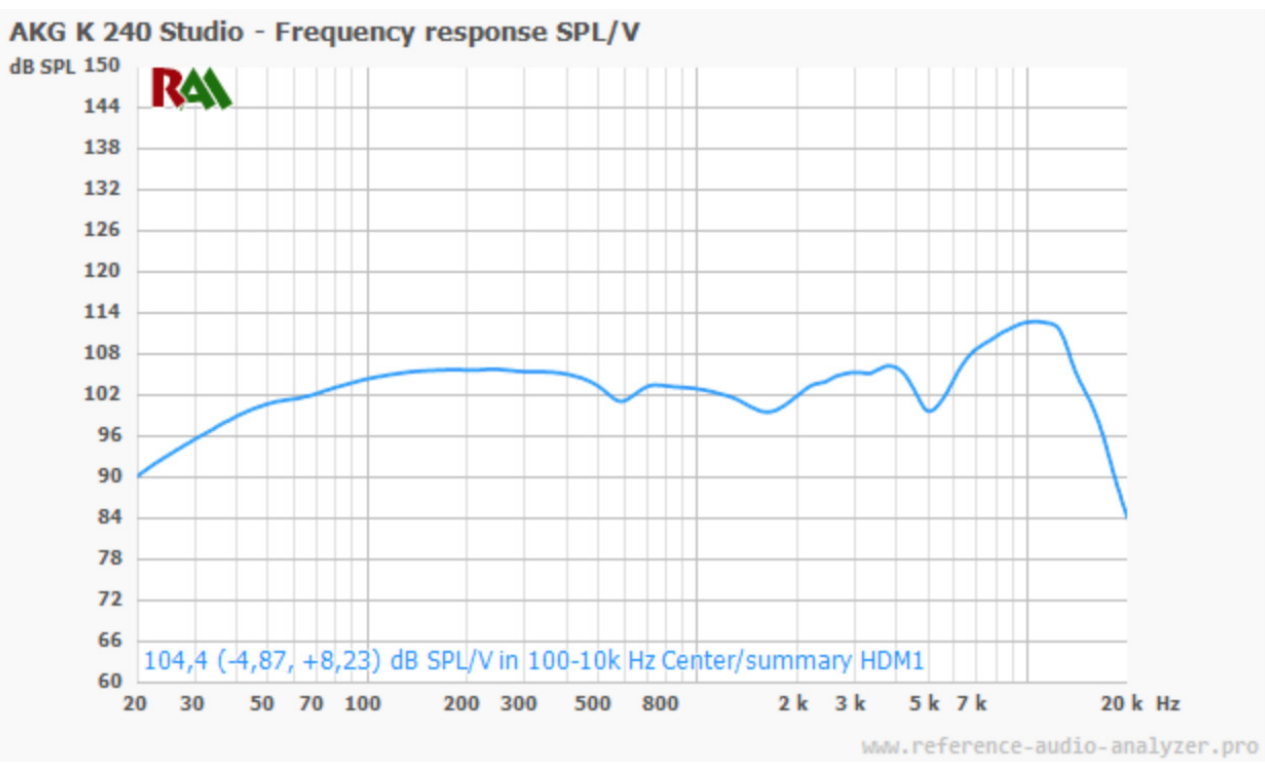

Fuente: Device Measurement Reports: AKG K 240 Studio report.

Como se observa en la figura 2, la respuesta de frecuencia se muestra estable en los $102 \mathrm{~dB}$ SPL desde los $70 \mathrm{~Hz}$ hasta los $6 \mathrm{kHz}$. Luego el audífono comienza a perder su estabilidad y acentúa las frecuencias entre los $7 \mathrm{kHz}$ y los $10 \mathrm{kHz}$. Por otro lado, el audífono tiene dificultades para mantener una respuesta uniforme en las bajas frecuencias, específicamente, entre 20 y $69 \mathrm{~Hz}$.

Analicemos ahora la capacidad de los audífonos para rechazar sonidos externos. Esta capacidad se puede dividir en tres categorías: audífonos abiertos (open back), semi-abiertos (semi open) y cerrados (closed back). Básicamente, los abiertos ofrecen una mejor traslación de espacialidad y sonido natural a expensas de permitir el ingreso de sonidos externos al oído. Estos audífonos necesitan un espacio muy silencioso, pero son los que mejor replican el sonido de altavoces en un estudio. En el otro extremo están los cerrados, que ofrecen un aislamiento muy superior a ruidos externos, con la desventaja de no replicar la espacialidad de los abiertos y afectar la imagen sonora estéreo, haciéndola más estrecha. La elección del audífono dependerá de factores externos como el nivel de ruido de la sala y desde luego, el costo. La tabla 2 sugiere audífonos probados por el autor y muestra sus especificaciones técnicas más relevantes. 
Tabla 2. Audífonos recomendados.

\begin{tabular}{|l|l|l|l|l|}
\hline Especificaciones & AKG K240 Studio & $\begin{array}{c}\text { Audiotecnica } \\
\text { ATM M40x }\end{array}$ & Sony MDR 7506 & $\begin{array}{l}\text { Beyerdynamic } \\
\text { DT 990 Pro }\end{array}$ \\
\hline Tipo & Semi abierto & Cerrado & Cerrado & Abierto \\
\hline Sensibilidad & $104 \mathrm{~dB} \mathrm{SPL}$ & $98 \mathrm{~dB} \mathrm{SPL}$ & $106 \mathrm{~dB} \mathrm{SPL}$ & $96 \mathrm{~dB} \mathrm{SPL}$ \\
\hline Potencia & $200 \mathrm{~mW}$ & $1600 \mathrm{~mW}$ & $1000 \mathrm{~mW}$ & $100 \mathrm{~mW}$ \\
\hline Impedancia & $55 \mathrm{ohms}$ & $35 \mathrm{hmm}$ & $63 \mathrm{ohms}$ & $250 \mathrm{ohms}$ \\
\hline Respuesta & $15-25000 \mathrm{~Hz}$ & $15-24000 \mathrm{~Hz}$ & $10-20000 \mathrm{~Hz}$ & $5-35000 \mathrm{~Hz}$ \\
\hline $\begin{array}{l}\text { Cable } \\
\text { desconectable }\end{array}$ & $\mathrm{Si}$ & $\mathrm{Si}$ & $\mathrm{No}$ & No \\
\hline Costo & $\$ 69$ & $\$ 99$ & $\$ 99.99$ & $\$ 179$ \\
\hline
\end{tabular}

Fuente: Elaboración propia.

De los contendientes mostrados en la tabla, hemos tenido el gusto de usar y escucharlos todos. Personalmente, poseo un par de los AKG y un par de los Audiotecnica, y puedo decir que prefiero escuchar en los primeros, sobre todo, por su construcción semi abierta. No obstante, para nuestro espectáculo hipotético me inclino por los Audiotecnica ATM M40x por las siguientes razones: al tener una impedancia más cercana a la de los receptores, teóricamente, al menos, la necesidad de volumen en el IEM será mínima. Por ser audífonos cerrados ofrecen más aislamiento acústico y tiene una mejor respuesta de bajos comparado con el AKG K240 Studio. Su diseño es confortable y resulta cómodo de usar por un periodo de dos o tres horas. Su sensibilidad es suficiente para manejar el rango dinámico del espectáculo sin llegar a distorsionar el sonido. Su respuesta de frecuencia es lo bastante plana como para que el ingeniero de mezcla detecte sonidos indeseables y pueda corregir antes de enviarla a la audiencia. A pesar de no ser el más barato, todavía tiene un precio accesible y es posible comprarlo en Costa Rica, en grandes volúmenes, a precio de costo. Por último, es posible reemplazar el cable de conexión en caso de deterioro e incluso, tiene la opción de conectar cables más cortos.

\section{Mucho ruido y... ¿cuántas nueces me dijo que costaba?}

Para ejemplificar el costo de hacer este sistema valoremos lo que necesitamos comprar partiendo del supuesto de que ya se posee una consola similar o igual a la Behringer X32 y una computadora igual o similar a la Apple iMac con Qlab 3. La tabla 3 muestra el costo de hacer este espectáculo con los dispositivos inalámbricos necesarios, con las marcas de los fabricantes Shure y Sennheiser, que se representan en nuestro país. 
Audífonos inalámbricos para un espectáculo teatral en Costa Rica: diseño de sistema para 96 espectadores

Tabla 3. Costo estimado de los sistemas de audio inalámbricos

\begin{tabular}{|l|l|l|l|l|l|}
\hline \multicolumn{7}{|c|}{ Sistema audífonos inalámbricos Sennheiser } \\
\hline \multicolumn{1}{|c|}{ Artículo } & \multicolumn{1}{|c|}{ Marca } & \multicolumn{1}{c|}{ Modelo } & Cantidad & Costo Unidad \$ & Costo Total \$ \\
\hline Transmisor & Sennheiser & SR 300 IEMG4 & 2 & 749 & 1498 \\
\hline Receptor & Sennheiser & EK 300 IEM G4 & 96 & 629 & 60384 \\
\hline Audífonos & Audiotecnica & M40x & 96 & 99 & 9504 \\
\hline Baterías & RadioShack & 2500 mA & 240 & 30 & 7200 \\
\hline Total sistema audífonos inalámbricos & & & 78586 \\
\hline
\end{tabular}

\begin{tabular}{|l|l|l|l|l|l|}
\hline \multicolumn{7}{|c|}{ Sistema micrófonos inalámbricos Sennheiser } \\
\hline \multicolumn{1}{|c|}{ Artículo } & \multicolumn{1}{|c|}{ Marca } & \multicolumn{1}{|c|}{ Modelo } & Cantidad & Costo Unidad \$ & Costo Total \$ \\
\hline Transmisor* & Sennheiser & SK 100 G4 & 20 & 599 & 11980 \\
\hline Receptor $^{\star}$ & Sennheiser & EM 100 G4 & 20 & & \\
\hline Micrófono** & Countryman & B3 para Sennheiser & 20 & 219 & 4380 \\
\hline Baterías & RadioShack & 2500 mA & 60 & 30 & 1800 \\
\hline Total sistema micrófonos inalámbricos & & & 18160 \\
\hline
\end{tabular}

*Se pueden comprar ambos artículos como un paquete.

${ }^{*}$ El paquete ya incluye un micrófono de solapa, pero este no es el adecuado para espectáculos teatrales.

\begin{tabular}{|l|l|l|l|l|l|}
\hline \multicolumn{7}{|c|}{ Sistema audífonos inalámbricos Shure } \\
\hline \multicolumn{1}{|c|}{ Artículo } & \multicolumn{1}{|c|}{ Marca } & \multicolumn{1}{|c|}{ Modelo } & Cantidad & Costo Unidad \$ & Costo Total \$ \\
\hline Transmisor & Shure & P9T & 2 & 649 & 1298 \\
\hline Receptor & Shure & P9RA & 96 & 590 & 56640 \\
\hline Audífonos & Audiotecnica & M40x & 96 & 99 & 9504 \\
\hline Baterías & RadioShack & 2500 mA & 240 & 30 & 7200 \\
\hline Total sistema audífonos inalámbricos & & & 74642 \\
\hline
\end{tabular}




\begin{tabular}{|c|c|c|c|c|c|}
\hline \multicolumn{6}{|c|}{ Sistema micrófonos inalámbricos Shure } \\
\hline Artículo & Marca & Modelo & Cantidad & Costo unidad \$ & Costo total \$ \\
\hline Transmisor ${ }^{\star}$ & Shure & BLX1 & 20 & \multirow{2}{*}{549} & \multirow[t]{2}{*}{10980} \\
\hline Receptor* & Shure & $\mathrm{BLX} 4 \mathrm{R}$ & 20 & & \\
\hline Micrófono** & Countryman & B3 para Shure & 20 & 186 & 3720 \\
\hline Baterías & RadioShack & $2500 \mathrm{~mA}$ & 60 & 30 & 1800 \\
\hline \multicolumn{5}{|c|}{ Total sistema micrófonos inalámbricos } & 16500 \\
\hline \multicolumn{5}{|c|}{ Inversión total de sistemas inalámbricos Shure en \$ } & 91142 \\
\hline
\end{tabular}

*Se pueden comprar ambos artículos como un paquete.

${ }^{\star}$ EEl paquete ya incluye un micrófono de solapa, pero este no es el adecuado para espectáculos teatrales.

Fuente: Elaboración propia.

Obtenemos de estos costos aproximados que, si se quiere montar Hamlet con un sistema Sennheiser en su totalidad es necesario invertir \$175 332 en 96 audífonos inalámbricos para la audiencia y 20 micrófonos inalámbricos para los actores. En caso de que el espectáculo fuera capturado binauralmente, el costo total sería de $\$ 86586$. Si se desea hacer el espectáculo con sistemas Shure en su totalidad, la inversión asciende a \$165 784 para 96 audífonos y 20 micrófonos inalámbricos. Si el espectáculo es binaural, la producción debe invertir \$82 642. Es importante mencionar que los actores deberán tener monitoreo de algún tipo para poder escuchar los pies de sonido en el escenario. Para abaratar costos en nuestro hipotético espectáculo, incluiremos dos altavoces calibrados a un volumen lo suficientemente alto, que permite la escucha por parte de los actores y que, al mismo tiempo, se filtre mínimamente en los micrófonos inalámbricos.

En el FOH, la mezcla podrá hacerse en altavoces o audífonos. Solo para mantener la simplicidad, se recomienda usar audífonos, pero, afortunadamente, la mesa X32 nos ofrece salidas de monitor para conectar un par de altavoces. Si el espectáculo es enteramente hecho en estéreo, recomiendo hacer la mezcla en altavoces. Es bien aceptado que la mezcla en altavoces se traslada muy bien en audífonos, especialmente, la sensación de profundidad y espacialidad. En todo caso, no duele que la mezcla sea hecha monitoreando el material en ambos medios: audífonos y altavoces. Si, por el contrario, el espectáculo fuera en su totalidad binaural o tuviera secciones en binaural, la mezcla debería hacerse en audífonos debido a que este tipo de captura no suena ni genera la misma sensación de espacialidad en los altavoces. Note, sin embargo, que el fabricante Neumann declara que su micrófono KU-100 "se traslada bien en altavoces" (Neumann, 2018). Debe evaluar el diseñador con sus propios oídos si tal afirmación es verdadera. 
Por último, el diseñador de sonido debe cerciorarse de que los transmisores y receptores estén configurados para recibir pilot tone. Este tono se encuentra localizado en los 19 $\mathrm{kHz}$. Sirve, mayormente, para que el receptor decodifique la señal estéreo, de otro modo, el receptor modulará una señal mono o degradará la señal estéreo. Sigismondi (2015) recomienda que las mezclas no tengan hard panning o que las fuentes sonoras no estén dispuestas totalmente a la izquierda o la derecha para garantizar una mejor transmisión de la imagen sonora (2015, pp. 1506-1507). Esto es especialmente importante si hay material sonoro y música pregrabada.

\section{Posibles implicaciones de este diseño en el espectáculo}

Ya que hemos ensamblado las partes, recordemos por un momento, cómo fluye la señal en nuestro espectáculo:

sala teatral $\rightarrow$ actores/micrófonos $\rightarrow$ reproducción de fuentes sonoras en computadora $\rightarrow$ mesa de mezcla $\rightarrow$ transmisores inalámbricos $\rightarrow$ receptores inalámbricos $\rightarrow$ audífonos $\rightarrow$ espectador

Sabiendo que la sala del Teatro Universitario tiene dificultades para rechazar sonidos intrusivos del exterior, pareciera que no es opción la utilización de micrófonos binaurales porque este micrófono captaría tanto los sonidos de afuera como los producidos dentro del teatro. Sin embargo, la belleza de hacer un espectáculo basado en audífonos es que el aislamiento acústico que estos crean permite poner sonidos en la cabeza del espectador, sin que necesariamente exista una fuente real que los produzca. Es decir, un personaje como El Fantasma del Rey Hamlet puede cobrar mayor protagonismo utilizando un micrófono binaural, el cual permite recrear esta sensación de localización sonora adelante-atrás/arriba-abajo que no es posible lograr en estéreo. Entonces, este aspecto fantasmagórico se puede realzar haciendo que la voz del espectro gire en forma esférica en la cabeza del oyente, sin necesidad de un referente visual. Mientras que, la voz del actor que interpreta a Hamlet es capturada por su micrófono inalámbrico y esta se mantiene centrada en la imagen estéreo. Dicho de otro modo, es posible combinar ambos tipos de captación para generar una sola mezcla multidimensional que genere un efecto en el oyente que no es posible replicar con este nivel de precisión en altavoces convencionales.

Asimismo, el micrófono binaural puede utilizarse, también, para ubicar eventos sonoros a nivel espacial, de nuevo, sin necesidad de un referente visual en el escenario. Por ejemplo, un personaje que entra desde la esquina inferior derecha del escenario por una puerta. La sola convención de escuchar una puerta que abre inmediatamente nos hace pensar como espectadores que alguien habrá de entrar por ella. Con la ayuda de un micrófono binaural y audífonos es posible, además, precisar desde donde se produce ese sonido de 
la puerta invitando al espectador a mirar hacia el lugar donde se produce la fuente, incluso si ese sonido jamás fue producido en el escenario. Para lograr estos efectos, es necesario recordar que el sonido binaural replica la audición humana, por ende, la ubicación de los sonidos en el audio binaural debe hacerse en correspondencia hacia donde mira la audiencia. Mejor dicho, que la izquierda, la derecha, el arriba y el abajo del espectador correspondan también a la del micrófono binaural.

El sonido estéreo, aunque convencional, permitirá tener presentes las voces de los actores que ahora se benefician de interpretar sus líneas de una forma más íntima y natural, cinematográfica si se quiere, puesto que la necesidad de proyectar la voz hasta la última butaca ya no es necesaria. La música se beneficia del sonido estéreo puesto que no es referencial. O sea, no es tan importante saber de dónde o quién produce el sonido del piano, sino lo que produce emotivamente. Los efectos sonoros pueden ser preproducidos tanto en el formato estéreo como en el binaural.

Por último, el volumen promedio del espectáculo deberá ser decidido de antemano para garantizar un sonido uniforme durante la duración del evento, así como preservar su rango dinámico. Por rango dinámico entendemos que el sonido subirá y bajará de volumen de acuerdo con los eventos y sucesos presentados en la obra. En los pasajes tranquilos es de esperarse que el volumen sea bajo o medio, mientras que, en el clímax de la obra el volumen aumente casi llegando hasta su límite máximo. Determinar este volumen y su rango dinámico es, en sí mismo, un objeto de estudio ampliamente investigado, el cual no abordaremos en detalle acá, pero si mencionaremos algunos aspectos elementales.

Como los estudios de Fletcher-Munson demostraron hace ya casi un siglo, la audición humana no es lineal y su percepción de las frecuencias varía de acuerdo con el volumen en que estas se reproduzcan, al ser la banda entre los 500 y $4000 \mathrm{~Hz}$ la más estable. Coincidentemente, la voz humana suele ubicarse, mayormente, en este rango de frecuencias, por lo que, anatómicamente hablando, el oído humano está diseñado para ser sensible a la voz humana y de rebote, a estas frecuencias. Las frecuencias fuera de este rango sensible del ser humano se ven mucho más afectadas por la intensidad, o volumen a la que estas suenan. Cuando Fletcher y Munson hicieron sus experimentos, notaron que, a volúmenes muy bajos el oído humano es ineficiente escuchando las bajas y altas frecuencias en comparación con las medias, a pesar de que el volumen de todas las frecuencias era el mismo.

Conforme se aumentaba la intensidad o volumen de todas las frecuencias, los científicos comenzaron a notar que los sujetos escuchaban mejor las frecuencias bajas y altas hasta llegar a un punto en donde se puede decir que, la mayor parte de los sujetos escuchaban bandas de frecuencia bajas, medias y altas al mismo volumen, cuando, efectivamente, todas estas bandas estaban dispuestas al mismo nivel. Estas mediciones arrojaron 
Audífonos inalámbricos para un espectáculo teatral en Costa Rica:

Artículos diseño de sistema para 96 espectadores

que el ser humano estabiliza su percepción de las frecuencias hacia los 80 dB SPL, a pesar de que las intensidades menores son las que experimentan un recorte de las bandas bajas y altas, y las intensidades mayores son las que experimentan un incremento a pesar de que el aumento de volumen sea parejo para todas las frecuencias. Como conclusión, los científicos descubrieron que la audición es subjetiva y que, para lograr una estabilización de todo el espectro se debía llegar a un volumen específico. Luego, este nivel se tomó como referencia para medir cuanto tiempo puede una persona soportar sonido continuo sin fatigarse o experimentar dolor y, consecuentemente, sordera. Se determinó que 85 dB SPL es un nivel soportable hasta por 8 horas continuas y que exposiciones mayores a $85 \mathrm{~dB}$ SPL son solo posibles en el marco de una hora o pocos minutos.

Entonces, ¿cómo esta información afecta el desempeño de nuestro diseño? Tanto el diseñador de sonido como el ingeniero de mezcla serán los responsables de enviar una copia exacta del sonido que ellos producen en el FOH a todos los audífonos de la audiencia. Para poder determinar un correcto balance de volumen entre los diálogos de los actores, la música, efectos y ambientes sonoros se hace necesario calibrar todos los audífonos al mismo nivel, el cual será $80 \mathrm{~dB}$ SPL. Este nivel se refiere al volumen continuo y no al momentáneo, mejor conocido como "pico", dado que el oído necesita cierto margen de tiempo para determinar un sonido como "bajo" o "alto". Para determinar este volumen en los audífonos los receptores deberán recibir señal constante desde la mesa de mezcla (a través del transmisor) a un nivel de - $18 \mathrm{~dB}$ Full Scale (FS) o escala completa, puesto que trabajaremos con dispositivos digitales.

Contrario al sonido u ondas mecánicas acústicas, que empiezan en 0 dB SPL o umbral de la audición hasta los 144 dB SPL o umbral del dolor, el audio digital trabaja en una escala en donde la representación audible más baja de volumen se representa con un $-\infty$, mientras su máximo es de 0 dB FS. Dado que pasaremos sonido de un medio a otro' ${ }^{15} \mathrm{es}$ necesario garantizar que su nivel se mantenga constante a través de ellos. Así, la constante de sonido en la mesa de mezcla deberá marcar -18 dB FS. Este nivel, a su vez, deberá marcar lo mismo, tanto en el transmisor y el receptor inalámbrico. Finalmente, la perilla de volumen en el receptor deberá girarse hasta que el sonido emitido en los audífonos llegue a los 80 dB SPL. Para evitar confusiones, debemos recordar que dB SPL mide la intensidad de volumen de las ondas acústicas en el aire. Mientras que dB FS indica los niveles de volumen en un medio digital.

${ }^{15}$ Los medios son: acústico con los audífonos, electrónico por la conversión de las ondas acústicas a impulsos eléctricos, digital porque la mesa convierte esas fuentes en audio digital, electrónico por los transmisores y receptores IEM y acústico de nuevo con los audífonos.

ESCENA. Revista de las artes, 2019, Vol. 79, Núm. 1 (julio-diciembre), pp. 145-176 
Esta práctica permite tener techo dinámico. Al ubicarse la media de volumen a -18 dB FS en la mesa, los audífonos $80 \mathrm{~dB}$ SPL, dejándonos un margen o techo de $18 \mathrm{~dB}$ en ambos lados, para aumentar el volumen sin llegar a la distorsión. Esto quiere decir que, si los diálogos de los actores ingresan a la mesa a -18 dB FS y en los audífonos suenan a 80 dB SPL, cuando agreguemos música y otros elementos sonoros, los niveles de volumen sumados podría llegar hasta los -8 dB FS, lo cual se traduce en los audífonos en 90 dB SPL. Aún tendríamos $8 \mathrm{~dB}$ de techo, para incrementar el volumen. Estos aumentos de volumen los podemos reservar para momentos cortos de nuestro espectáculo, como explosiones o el gran final de la obra en donde habrá música, diálogos y efectos de sonido. De este modo, el mayor volumen posible en nuestro espectáculo es $98 \mathrm{~dB}$ SPL $(80 \mathrm{~dB}+18 \mathrm{~dB}$ de techo dinámico), la media de 80 dB SPL y, desde luego, niveles más bajos que esto, con la ventaja de que serán percibidos por la audiencia sin problema.

\section{Conclusiones}

Queda evidenciado que es posible crear un espectáculo teatral en el que se transmita sonido a unos audífonos de forma inalámbrica para más de 96 espectadores en Costa Rica. Pero, se evidencia, también, que la inversión para un espectáculo de este tipo necesita una cantidad considerable de dinero. Aunque el documento utiliza 96 espectadores para establecer su diseño, no sugiere que esta implementación no sea posible para teatros de menor capacidad, como la Sala Vargas Calvo, sin dejar de tener los mismos beneficios o resultados. De ahí el valor de presentar una propuesta de diseño y la forma en que los dispositivos se comunican entre sí.

La transmisión inalámbrica supone una instalación sencilla y libre de cables dentro del inmueble, lo que facilita el libre tránsito de los espectadores, en caso de que tal necesidad se manifieste como parte de la propuesta. Se expone, también, que la posibilidad de explotar las ventajas de aislamiento acústico que ofrecen los audífonos combinadas con la captación y reproducción de sonidos, en formato binaural mezclados de forma conjunta con el tradicional sonido estéreo, expanden las posibilidades sonoras de creación artística que no son posibles de replicar en sistemas basados en altavoces, como los que hay en nuestros teatros costarricenses.

Como mencionamos antes, el uso de micrófonos permite que los actores entreguen una actuación más enfocada en la interpretación del texto y no en la proyección de la voz. Esta ventaja se evidencia aún más a través de la escucha de estos parlamentos en los audífonos que, a su vez, permiten elevar el volumen de captación de los micrófonos al eliminar la retroalimentación, o feedback, que resulta difícil de controlar cuando se usan altavoces. Otro aspecto importante que concluye este documento es que no restringe el formato de mezcla 
Audífonos inalámbricos para un espectáculo teatral en Costa Rica:

Artículos diseño de sistema para 96 espectadores

que ha de entregarse a los espectadores, sino que invita a combinarlos (binaural o estéreo). La zona segura es hacer un espectáculo basado en el tradicional estéreo y, de ser posible, agregar un micrófono binaural, ya sea para pregrabar sonidos y luego reproducirlos en el espectáculo, o bien, usarlo como generador de efectos sonoros tridimensionales en vivo.

Por último, es tarea del diseñador determinar el volumen promedio del espectáculo para que su emisión a través de los audífonos sea placentera. A pesar de que los receptores IEM ofrecen la opción de ajustar el volumen de cada receptor, determinar el volumen promedio no solo asegura tener consistencia entre la emisión y recepción del material auditivo a transmitir, sino, también ayuda a la audiencia a mantenerse enfocada en el espectáculo y no distraerse en ajustar el volumen de sus receptores. Esto ya sea porque el volumen es excesivo y aturde o porque es tan bajo que pierde detalle de elementos fundamentales como el dialogo actoral.

\section{Referencias}

Auditry. (2014). Tool. Recuperado de http://auditry.blogspot.com/2014/02/headphone-amp-power-calculator.html

BBC Click. (22 de Abril de 2016). YouTube. BBC Click [Video]. Recuperado de: https://www.youtube.com/watch?v=51za5u3LtEc

DigiZoid Inc. (2009-2014). Tools. Recuperado de http://www.digizoid.com/headphones-power.html

Engstrom, M. (22 de Mayo de 2013). Understanding Headphone and Earphone Specifications (C. Lyons, Entrevistador) [Entrevista en video]. Recuperado de: https://www.youtube.com/watch?time_continue $=272 \& v=5 \mathrm{MWk} 7 \mathrm{jejh} \times \mathrm{Q}$

Gimenez, M. (9 de de octubre de 2018). Headphone Theatre-A Primer. No Proscenium [Entrada de blog].Recuperado de: https://noproscenium.com/headphone-theatre-a-primer-520b4d2a3f46

Huntington, J. (2012). Show Networks \& Control Systems. Nueva York: Zircon Designs Press.

Klich, R. (3 de November de 2017). Amplifiyng Sensory Spaces: The In-and Out- Puts if Headphone Theatre. Contemporary Theatre Review(27), 366-378.

Neumann. (9 de de octubre de 2018). KU-100, Dummy Head. Microphones [página web]. Recuperado de: https://en-de.neumann.com/ku-100

Reesman, B. (9 de de de 2018). (Re)Creating The Encounter. Stage Directions [página web]. Recuperado de: http://stage-directions.com/current-issue/61-sound.../9035-recreating-the-encounter.html

ESCENA. Revista de las artes, 2019, Vol. 79, Núm. 1 (julio-diciembre), pp. 145-176 
Reference Audio Analizer Pro. (s.f.). Device Measurement Reports: AKG K 240 Studio report. Reference Audio Analizer Pro [Imagen]. Recuperado de https://reference-audio-analyzer.pro/en/report/hp/akg-k-240-studio.php

Schauspielhaus Zürich. (2018). Beute Frauen Krieg [página web]. Recuperado de https://www.schauspielhaus.ch/de/play/953-BEUTE-FRAUEN-KRIEG

Sennheiser. (2018). Sennheiser. ew 300 IEM G3 [página web]. Recuperado de https://enuk.sennheiser.com/wireless-microphone-live-monitoring-system-ew-300-iem-g3

Shure America. (2016). Headphone Specifications/Supoort/Frequently Asked Questions. Understanding Earphone [página web]. Recuperado de http://www.shure. com/americas/support/find-an-answer/understanding-earphone-headphone-specifications

Shure America. (23 de Agosto de 2018). PSM 900 Personal Monitoring System [página web]. Recuperado de http://www.shure.com/americas/support/find-an-answer/ can-i-use-more-than-one-psm-receiver-with-just-one-transmitter

Sigismondi, G. (2015). Personal Monitoring Systems. En A. E. Society, \& G. Ballou (Ed.), Handbook for Sound Engineers. Londres: Taylor and Francis. Kindle Edition.

Trueman, M. (9 de octubrede 2018). Warning: this play contains headphones. The Guardian, Theatre Blo [entrada de blog]: Recuperado de https://www.theguardian. com/stage/theatreblog/2009/dec/08/headphone-play-audio-theatre 
Anexo

Figura 2. Resumen del diseño de audifonos inalámbricos para 96 expectadores

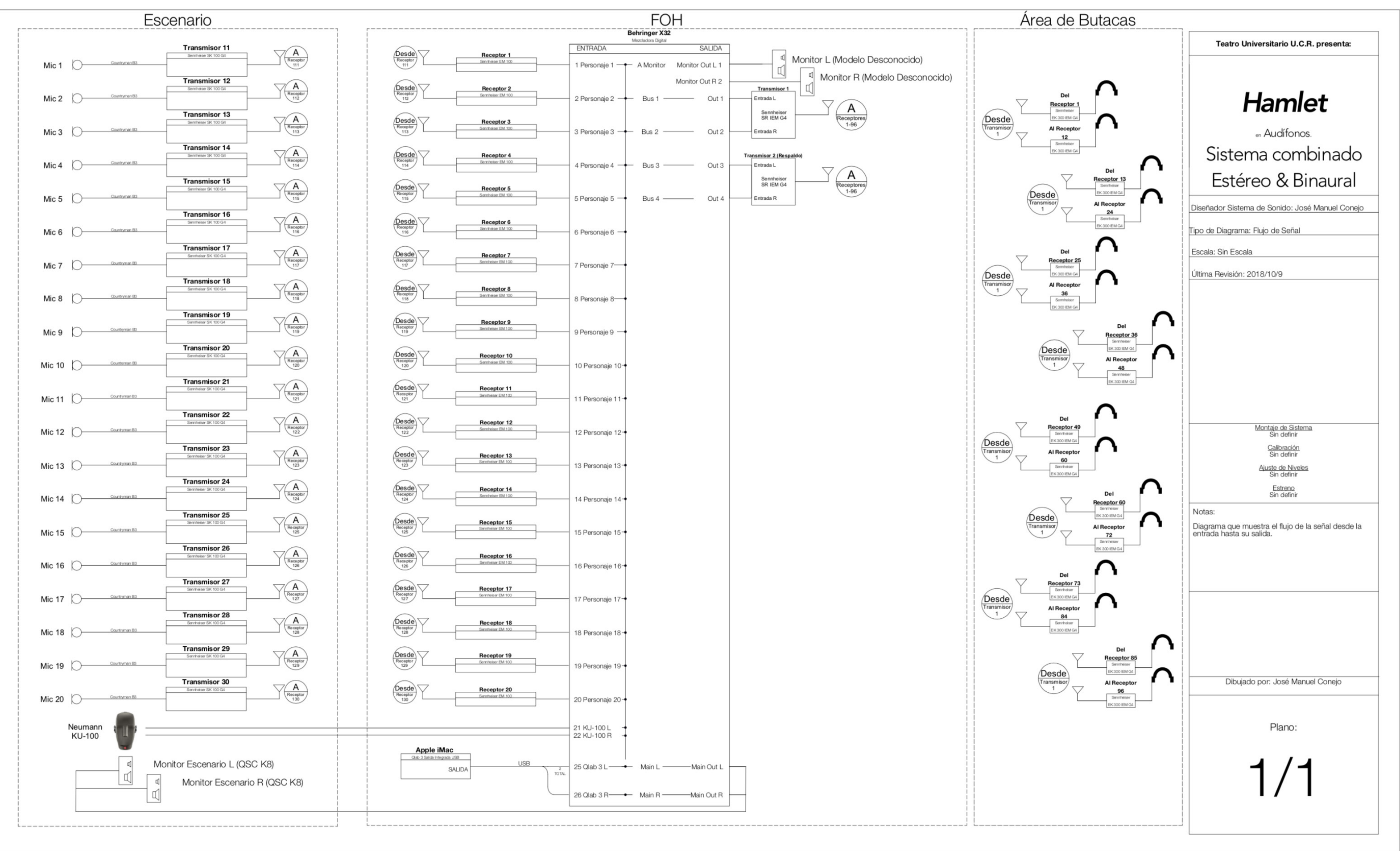

Fuente: Elaboración propia. 